Part of Journal of Research of the National Bureau of Standards, Volume 16, March 1936

\title{
REVERSAL TEMPERATURE AND POPULATION OF EXCITED STATES IN THE CESIUM DISCHARGE
}

\author{
By Fred L. Mohler
}

\begin{abstract}
Light from a tungsten strip lamp was projected through the positive column of a cesium discharge onto the slit of a spectrograph, and the lamp temperatures determined at which the cesium lines disappeared against the continuous background. Measurements were made on the lines $6 \mathrm{~S}-6 \mathrm{P}$ to $6 \mathrm{~S}-11 \mathrm{P}$ at different pressures and discharge currents. The reversal temperature decreases from the first to the third line and beyond the third there is no measurable difference. It increases with increasing current and with decreasing pressure. The number of atoms in an excited state is given by an equation of the form of the Boltzmann equation, with the reversal temperature replacing the equilibrium temperature. The number per cubic centimeter ranges in magnitude from $10^{12}$ for the first $\mathrm{P}$ state to $10^{6}$ for the highest states. In the range of conditions studied it was independent of pressure at constant current.
\end{abstract}

\section{CONTENTS}

I. Introduction

II. Experimental procedure

III. Results

\section{INTRODUCTION}

The number and distribution of atoms in excited states is an important factor in determining the intensity distribution of radiation in the spectrum of a discharge, and it must also influence the electrical characteristics of the discharge. Published measurements of the number of excited atoms deal for the most part with the first excited state. A notable exception is the studies of the anomalous dispersion in the neon discharge by Kopfermann and Ladenburg. ${ }^{1}$ They found that the number of atoms in the first group of excited states (the Paschen $1 s$ states) is about equal to the number in equilibrium at a temperature equal to the electron temperature. With the highest current attainable the group of $2 p$ levels also approach this equilibrium value, but levels of higher energy are always far below it.

In a paper on collisions ${ }^{2}$ of the first and second kind in the positive column of a cesium discharge I have included measurements of the number of atoms in the first and second $\mathrm{P}$ states $\left(6^{2} \mathrm{P}\right.$ and $\left.7^{2} \mathrm{P}\right)$ using the method of reversal temperatures. This paper reports an extension of the measurements to higher lines of the principal series.

1 Kopfermann and Ladenburg, Z. Phys. 48, 15, 26, 51, and 192 (1928); 65, 167 (1930); Naturwissenschaften 19, p. 513; 1931.

Mohler, BS J. Research 9, 493 (1932) RP485.

$49283-36-2$ 
The principle of the reversal-temperature measurement is as follows: If the image of an incandescent lamp is projected through a tube of gas or vapor onto the slit of a spectrograph, absorption lines of the gas will appear as dark lines. If the gas is electrically or thermally excited so as to be self-luminous the lines may appear either darker or brighter than the continuous background, and there is at least theoretically a lamp temperature at which the lines will disappear. (In practice this is often too high to attain with an incandescent lamp.) This is called the reversal temperature.

It can be shown ${ }^{3}$ on the basis of elementary radiation theory that for a uniformly excited volume of gas the number of atoms per unit volume in an excited state $N_{2}$ of energy $E_{2},{ }_{1}$ is related to the number in the lower state $N_{1}$ by the equation:

$$
N_{2}=N_{1}\left(g_{2} / g_{1}\right) \exp \left(-E_{2}, 1 / k T\right),
$$

where the $g$ 's are the weights of the two states, and $T$ is the reversal temperature. This equation is identical in form with the Boltzmann

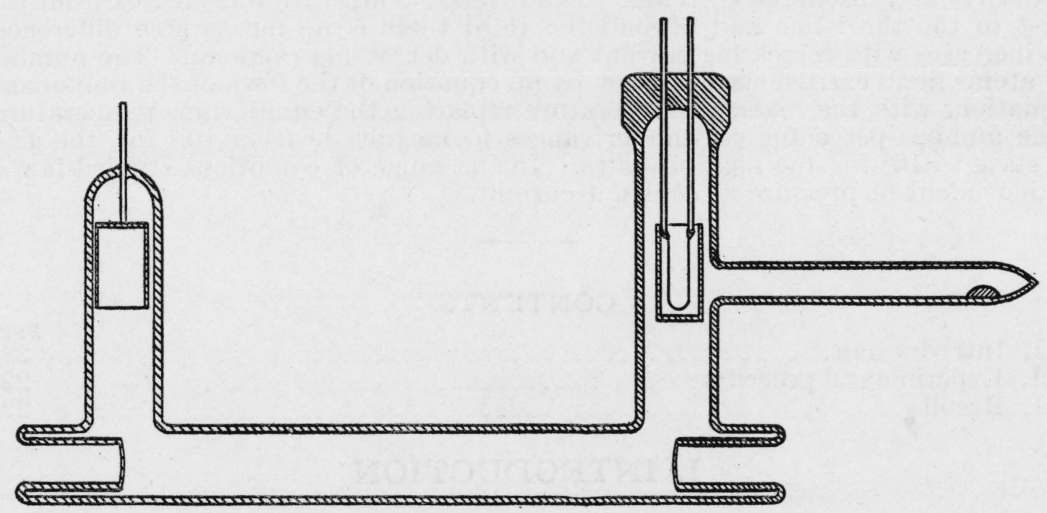

FIgURE 1.-Discharge tube used to measure reversal temperature.

equation, but it involves no assumption as to equilibrium and where there is not equilibrium different lines may give different values of $T$. $T$ is quite independent of the strength of the absorption but the sensitivity of the method depends on the absorption.

\section{EXPERIMENTAL PROCEDURE}

Measurements were made with a columnar discharge in a tube of the shape shown in figure 1. The tube was $1.8 \mathrm{~cm}$ in diameter and the distance between the windows was $24 \mathrm{~cm}$. The windows were in the discharge to avoid a reversing layer. Thin blown Pyrex windows were better than fused quartz, but discoloring of the windows by the alkali remained a source of error. The light from a gas-filled tungsten strip lamp passed along the axis of the tube. It was focused near the center of the tube and focused on the slit of the spectrograph by quartz fluorite achromats. A Hilger E1 quartz spectrograph was used.

\footnotetext{
8 Hedwig Kohn, Phys. Z. 29, 49 (1928).
} 
Corrections to be applied to the light intensity were measured by photographic densitometry. The brightness temperature of the image formed by the first lens within the discharge tube gives the true value of $T$. The tube was replaced by a quartz strip lamp to measure the ultraviolet intensity of the image. The tube was then put in place and the change in brightness measured. Half this change was taken to be the correction for one tube window. There is also a correction for the difference in emissivity of the tungsten in the ultraviolet as compared with the red, for the calibration of the quartz lamp was as usual in terms of red light. The sum of the corrections was a function of the wave length. Extreme values were

$$
\begin{aligned}
& 1 / T \text { (image) }-1 / T(\text { lamp })=.27 \times 10^{-4} \text { at } 4555 \mathrm{~A} . \\
& 1 / T \text { (image) }-1 / T(\text { lamp })=.30 \times 10^{-4} \text { at } 3400 \mathrm{~A} \text {. }
\end{aligned}
$$

The procedure was to obtain a series of spectrograms with constant discharge conditions and with different currents in the strip lamp. Inspection showed which lamp current was closest to a match for each line and the calibrated temperature with the above correction gave the reversal temperature.

Good sensitivity and values of $T$ within the range of the lamp could only be obtained in a limited range of discharge conditions. It required a number of trial exposures to find the useful range of lamp temperatures and exposure times. (Exposures ranged from 30 seconds to 30 minutes.) With the preliminary experience 8 or 10 exposures gave the reversal temperatures of all lines for one discharge condition. There is an uncertainty of at least $30^{\circ}$ in picking the reversal temperature and there may be an equal or greater systematic error in the method used.

\section{RESULTS}

Table 1 summarizes the results and includes for comparison published values ${ }^{4}$ of the reversal temperatures for the first doublet in the infrared and the electron temperature as obtained from probe

\begin{tabular}{|c|c|c|c|c|c|c|c|c|c|}
\hline \multirow[b]{2}{*}{ Pressure } & \multirow[b]{2}{*}{ Current } & \multirow{2}{*}{$\begin{array}{l}\text { Electron } \\
\text { temper- } \\
\text { ature }\end{array}$} & \multicolumn{7}{|c|}{ Reversal temperatures, in ${ }^{\circ} \mathrm{K}$} \\
\hline & & & $\begin{array}{l}8521 \mathrm{~A} \\
6 \mathrm{~S}-6 \mathrm{P}\end{array}$ & $\begin{array}{l}4555 \mathrm{~A} \\
6 \mathrm{~S}-7 \mathrm{P}\end{array}$ & $\begin{array}{l}3877 \mathrm{~A} \\
6 \mathrm{~S}-8 \mathrm{P}\end{array}$ & $\begin{array}{l}3612 \mathrm{~A} \\
6 \mathrm{~S}-9 \mathrm{P}\end{array}$ & $\begin{array}{l}3477 \mathrm{~A} \\
6 \mathrm{~S}-10 \mathrm{P}\end{array}$ & $\begin{array}{l}3398 \mathrm{~A} \\
6 \mathrm{~S}-11 \mathrm{P}\end{array}$ & $\begin{array}{l}\text { Limit- } \\
\text { ing } \\
\text { value }\end{array}$ \\
\hline $\begin{array}{c}\mu \\
350, \\
3500 \\
350\end{array}$ & $\begin{array}{l}\underset{2}{\operatorname{amp}} \\
\stackrel{1}{1} .5\end{array}$ & $\begin{array}{l}{ }^{\circ} \mathrm{K} \\
2,520 \\
2,320 \\
2,150\end{array}$ & $\begin{array}{l}2,260 \\
2,090 \\
1,950\end{array}$ & $\begin{array}{l}2,160 \\
2,020 \\
1,885\end{array}$ & $\begin{array}{l}2,115 \\
1,985 \\
1,860\end{array}$ & $\begin{array}{l}2,115 \\
1,970 \\
1,860\end{array}$ & $\begin{array}{r}2,140 \\
1,970\end{array}$ & - & $\begin{array}{l}2,115 \\
1,970 \\
1,860\end{array}$ \\
\hline $\begin{array}{l}160 \\
160 \\
160\end{array}$ & $\begin{array}{l}2 \\
1 \\
.5\end{array}$ & $\begin{array}{l}2,550 \\
2,380 \\
2,120\end{array}$ & $\begin{array}{l}2,400 \\
2,230 \\
2,140\end{array}$ & $\begin{array}{l}2,240 \\
2,075 \\
1,985\end{array}$ & $\begin{array}{l}2,220 \\
2,058 \\
1,938\end{array}$ & $\begin{array}{r}2,200 \\
2,030 \\
-\end{array}$ & $\begin{array}{l}2,205 \\
2,045\end{array}$ & $\begin{array}{l}2,218 \\
2,050\end{array}$ & $\begin{array}{l}2,205 \\
2,030 \\
1,938\end{array}$ \\
\hline 76 & $\stackrel{2}{1} .5$ & $\begin{array}{l}2,640 \\
2,530 \\
2,380\end{array}$ & $\begin{array}{l}2,450 \\
2,340 \\
2,260\end{array}$ & $\begin{array}{l}2,340 \\
2,160 \\
2,090\end{array}$ & $\begin{array}{l}2,290 \\
2,110 \\
2,045\end{array}$ & $\begin{array}{l}2,280 \\
2,080 \\
2,045\end{array}$ & $\begin{array}{r}2,270 \\
2,080 \\
-\end{array}$ & $\begin{array}{r}2,270 \\
2,070 \\
-\end{array}$ & $\begin{array}{l}2,270 \\
2,080 \\
2,045\end{array}$ \\
\hline
\end{tabular}

TABLE 1.-Reversal temperatures for principal series lines of cesium

- Mohler, BS J. Research 9, 493 (1932) RP485. 
measurements. Beyond the second line of the series the reversal temperatures are constant within experimental error. This regularity is important from a theoretical viewpoint and permits a fairly safe extrapolation to the series limit. The reversal temperature increases with increasing current and with decreasing pressure.

Table 2 expresses the results in terms of the number of excited atoms per cubic centimeter in each state $n^{2} \mathrm{P}_{3} / 2$ by use of equation 1 . The negative exponent in the equation is always very large, ranging from 6.9 to 23.2 , so the number of atoms in each state decreases rapidly with increasing energy even for constant values of $T$. A second regularity appears in table 2. The number of atoms in a given state at constant current is about the same for different pressures. A test of this relation over a wide range of pressures is desirable.

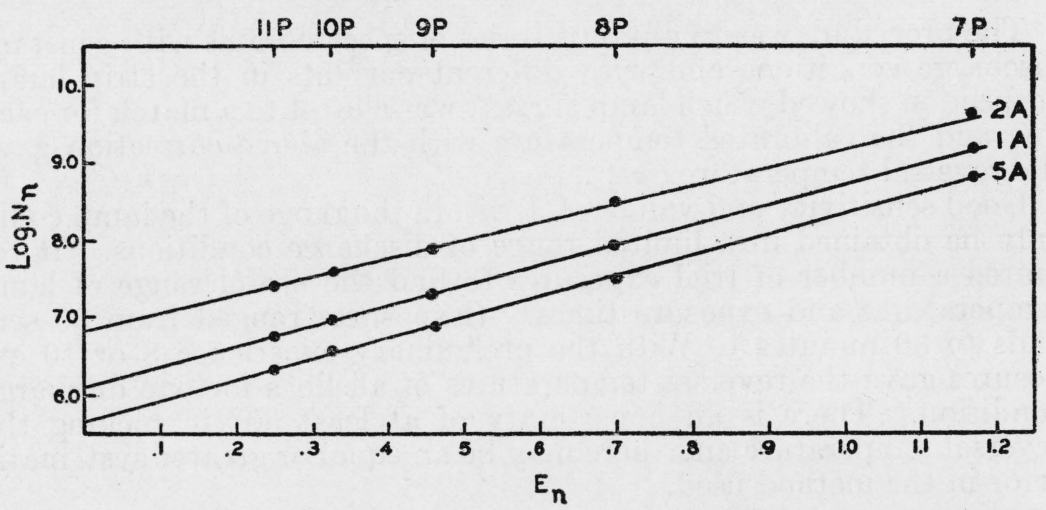

FIGURe 2.-Plot of the $\log$ of the number of atoms in each excited state $n \mathrm{P}_{3} / 2$ versus the negative energy of the state.

$E_{n}$ is in electron volts measured from the ionized state as origin.

TABLE 2.-Logarithms of the number of atoms in the states $n^{2} \mathrm{P}_{3} / 2$ per cubic centimeter

\begin{tabular}{|c|c|c|c|c|c|c|c|c|}
\hline $\log N_{a}$ normal state & $\begin{array}{l}\text { Cur- } \\
\text { rent }\end{array}$ & $\log N_{6}$ & $\log N_{7}$ & $\log N_{8}$ & $\log N_{\theta}$ & $\log N_{10}$ & $\log N_{11}$ & $\log N \widehat{\infty}$ \\
\hline $\begin{array}{l}15.73-17 \\
17.73 \\
17.73\end{array}$ & $\begin{array}{c}a m p \\
2 \\
1 \\
.5\end{array}$ & $\begin{array}{l}12.80 \\
12.54 \\
12.28\end{array}$ & $\begin{array}{l}\text { 9. } 71 \\
9.28 \\
8.79\end{array}$ & $\begin{array}{l}8.47 \\
7.96 \\
7.43\end{array}$ & $\begin{array}{l}7.90 \\
7.31 \\
6.79\end{array}$ & $\begin{array}{l}7.59 \\
6.96 \\
6.57\end{array}$ & $\begin{array}{l}7.39 \\
6.77 \\
6.21\end{array}$ & $\begin{array}{l}6.81 \\
6.13 \\
5.55\end{array}$ \\
\hline $\begin{array}{l}15.43 \\
15.43 \\
15.43\end{array}$ & $\begin{array}{l}2 \\
1 \\
.5\end{array}$ & $\begin{array}{l}12.69 \\
12.45 \\
12.32\end{array}$ & $\begin{array}{l}9.64 \\
9.16 \\
8.85\end{array}$ & $\begin{array}{l}8.53 \\
7.95 \\
7.47\end{array}$ & $\begin{array}{l}7.92 \\
7.37 \\
6.86\end{array}$ & $\begin{array}{l}7.62 \\
7.05 \\
6.51\end{array}$ & $\begin{array}{l}7.44 \\
6.85 \\
6.31\end{array}$ & $\begin{array}{l}6.82 \\
6.25 \\
5.62\end{array}$ \\
\hline 15.10 & $\begin{array}{l}2 \\
1 \\
.5\end{array}$ & $\begin{array}{l}12.42 \\
12.29 \\
12.17\end{array}$ & $\begin{array}{l}9.58 \\
9.08 \\
8.86\end{array}$ & $\begin{array}{l}8.41 \\
7.82 \\
7.52\end{array}$ & $\begin{array}{l}7.84 \\
7.14 \\
6.99\end{array}$ & $\begin{array}{l}7.54 \\
6.82 \\
6.68\end{array}$ & $\begin{array}{l}7.36 \\
6.62 \\
6.48\end{array}$ & $\begin{array}{l}6.81 \\
6.02 \\
5.86\end{array}$ \\
\hline $\begin{array}{l}\text { Energy of } n \mathrm{P} \text { states (electron } \\
\text { volts) }\end{array}$ & & 1. 45 & 2. 71 & 3.18 & 3.42 & 3.55 & 3.63 & 3.88 \\
\hline
\end{tabular}

The results of table 2 are plotted in figure 2. The mean of log $N_{n}$ for the three pressures is plotted as a function of the energy $E_{n}$. All results fall on three straight lines within experimental uncertainty, but theoretically the relation cannot be as simple as this. There is a real difference in temperature and therefore a real difference in slope 
at the different pressures, but it is too small to see on the scale shown. If the populations are equal for $8 \mathrm{P}$ they will not be equal at the limit and vice versa.

The nearly constant value of $T$ for higher series lines implies a nearly constant population of all states $n \mathrm{P}$ near the limit. This leads to an apparent paradox that is well recognized in the theory of distribution of energy in thermal equilibrium. ${ }^{5}$ If there are an infinite number of states the number of excited atoms is infinite. Actually the lines beyond about $n=20$ are completely fused together by pressure broadening and random Stark effect of ions. It seems reasonable to assume that only about 20 discrete ${ }^{2} \mathrm{P}_{3} / 2$ states exist and that for the 2 ampere discharge there are about $10^{7}$ atoms in each state above $n=11$ and in order of magnitude $10^{8}$ atoms in all $\mathrm{P}$ states above $n=11$. The number of atoms in the second state is then 10 times greater than in all higher $\mathrm{P}$ states, while the number in the first state is over 1,000 times that in the second state. The aggregate weight of every possible series term from $l=19$ to 0 is less than 1,000 times that of one $\mathrm{P}_{3} / 2$ term and, if it is assumed that all states are populated like the $\mathrm{P}$ states, there may be $10^{10}$ atoms in all the higher states. While these numbers are highly speculative it is worth while to see whether or not there are logical difficulties in extrapolating the experimental results and assuming that high energy states all have the same reversal temperature.

In spectroscopy it is commonly assumed that the initial states of a multiplet are populated in proportion to their statistical weight and experimental results confirm this for narrow multiplets. ${ }^{6}$ It does not follow that the higher terms of a series which are of equal weight will be equally populated. The considerations of the preceding paragraph show that the series of terms must terminate either gradually or abruptly at some finite value. It has been found that in a limited range of conditions the population of $\mathrm{P}$ states tends to approach a constant value with increasing quantum number but this result cannot be generalized without further experiment. A paper on intensities of emission lines now in preparation gives some further evidence as to the range of validity of this relation.

Washington, January 7, 1936.

${ }^{5}$ Ruark and Urey, Atoms, Molecules and Quanta, p. 712 (McGraw-Hill Book Co., New York).

6 See p. 697 of reference footnote 5. 